\title{
Emotional intelligence and effective leadership in hospitals
}

\author{
Marianela Mendoza ${ }^{\# 1}$, Raúl J. Martelo ${ }^{* 2}$, Diofanor Acevedo ${ }^{* 3}$ \\ \# Faculty of Social and Economic Sciences, University of the Zulia, Maracaibo, Zulia, Venezuela \\ ${ }^{1}$ marianelam_81@hotmail.com \\ *Faculty of Engineering, Faculty of Economics Sciences, \\ University of Cartagena, Cartagena, Bolívar, Colombia. \\ 2rmartelog1@unicartagena.edu.co \\ 3 diofanor3000@gmail.com
}

\begin{abstract}
The objective of the research was to establish what kind of relationship exists between emotional intelligence (EI) and effective leadership in heads of division of human resources and section supervisors in 4th level hospitals in the state of Zulia. The study was described as quantitative with a nonexperimental correlational design. Two questionnaires were used to determine existing characteristics of effective leadership and emotional intelligence, which showed a high degree of reliability using Pearson's statistical coefficient. A considerable positive correlation (0.79) between variables was determined. As a consequence, one characteristic to strengthen is EI for effective leadership.
\end{abstract}

Keyword - Competences, Self-awareness, Self-management, Motivation, Social Awareness, Relationship Management

\section{INTRODUCTION}

For the formation of a leader, they must possess distinctive characteristics such as: maturity, integrity, business acumen and social skills [1], in order to meet the expectations or goals of the entity. Therefore, it is evident that the leader needs to develop these characteristics, which are acquired in different ways, as expressed in [2], where it is stated that the characteristics of a leader can be acquired over time or be developed voluntarily by people. Similarly, [3] emphasize that leadership is the combination of experience and relationships maintained by the leader.

Leadership can be defined as a set of non-corrective processes to guide the individual or group towards certain goals [4]. In addition, the conceptualization of this topic has been affected by the results of studies, where it is defined as a system that operates at levels such as emotions, thoughts, values and virtues [5]. The above defines emotional leadership, which consists in managing the impressions of the group, so that the leader or boss is aware of the impact generated by their actions on the emotions of the Workgroup or followers [6].

An essential characteristic of the development of effective leadership is emotional intelligence [7], which is defined as the important skills in the expression and evaluation of one's own and / or others' emotions, in order to motivate the group [8]. This represents a fundamental role in leadership, because it increases production and improves the relationship between the boss and the worker [9]. Therefore, it is necessary to develop this intelligence, because it is related to leadership, as stated [10] who mentions that in a research conducted by the consultancy Hay/McBer, found 6 types of leadership: leadership with motivational authority, democratic leadership building a consensus through participation, step adjustment leadership hoping for excellence and selfdirection, leadership of coaching leaders and coercive leadership; which emerged from emotional intelligence.

Effective leadership has been applied in studies such as: for schools, in order to make them inclusive [11], in the evacuation of crowds according to the variables of the situational environment [12] and in the administration of resources for the construction of administrative institutions [13]. On the other hand, in the health sector, research is highlighted, such as [14], where they analyze leadership styles to determine the most variability in health care. In addition, [15] study the importance of effective leadership of the surgical team of cardiac surgery, in order to determine the behavior that best fits the team.

The analysis of effective leadership and its relationship with emotional intelligence in a hospital is fundamental, due to the implications of the work performed in these health centers and the quality of the service provided to patients. Taking into account the above, the objective of this research is to determine the relationship that exists between the variables. As a case study, hospitals were taken level 4th of Zulia state, in order to determine and promote leadership skills. 


\section{Methodology}

The research carried out was of a quantitative type, with a non-experimental, correlational design. Quantitative because its purpose was to find the relationship between emotional intelligence and effective leadership based on statistical data [16]. Not experimental because none of the variables were manipulated during the investigation [17]. Correlational, because it allowed to see the degree of relationship between emotional intelligence and effective leadership, in one or more groups of people [16].

\section{A. Population}

The population was conformed by: 1 head of human resources division and 7 section supervisors of the University Hospital of Maracaibo, 1 head of human resources division and 6 section supervisors of the Hospital General del Sur. For the determination of the sample, population census was applied, because the size of the population was small.

\section{B. Techniques and data collection instrument}

Two questionnaires were carried out, the first consisting of 28 emotional intelligence questions and the other 50 effective leadership questions. These were structured with a Likert scale: never, almost never, sometimes and always. In addition, scales were assigned a value, with the purpose of categorizing the answers into a scale, which is found in Table 1.

TABLE I. Interpretive range

\begin{tabular}{|c|c|}
\hline Range & Category \\
\hline $1-2.33$ & Low \\
\hline $2.34-3.67$ & Half \\
\hline $3.68-4.00$ & High \\
\hline
\end{tabular}

\section{Validity and reliability of the instrument}

Once the information collection instruments were designed, they were tested in order to determine their validity and reliability. To measure the degree of reliability, the Cronbach's alpha coefficient was used, which was used to measure the relationship between questionnaire questions [18].

$$
r t=\left[\frac{k}{k-1}\right]\left[1-\frac{S_{i}{ }^{2}}{S_{t}{ }^{2}}\right]
$$

$\mathrm{rtt}=$ coeficiente alfa Cronbach

$k=$ número de preguntas

$\mathrm{S}_{\mathrm{i}}^{2}=$ varianza de los puntajes de cada pregunta

$\mathrm{S}_{\mathrm{t}}^{2}=$ varianza de los puntajes totales

The results obtained showed a reliability for the intelligence questionnaire of 0.84 (very high) and for the effective Leadership of 0.94 (very high), which indicated that the instruments used provided reliable data for the investigation.

On the other hand, to evaluate the relationship between emotional intelligence and effective leadership, Pearson's statistical coefficient was used, because it allows knowing what is the linear association between the variables but not which influences the other [19].

\section{Técnicas de análisis de datos}

The data collected regarding effective leadership and emotional intelligence in the hospitals of the 4th level of the state of Zulia, were analyzed through the use of descriptive statistics, indicators, dimensions and variance. In addition, its absolute and relative frequency, and central tendencies such as the mean and the dispersion measure were obtained. 


\section{III.RESULTS}

The dimensions evaluated in the questionnaire of the Emotional Intelligence variable were divided into two sections: Intrapersonal Competences and Interpersonal Competences, which indicate the ability to know one's own and others' emotions. The intrapersonal competence has three indicators evaluated: self-awareness, selfmanagement and motivation. Likewise, Interpersonal Competencies are divided into Social Awareness and Relationship Management. The results obtained for the intrapersonal competences dimension are shown in Table 2.

TABLE II. Intrapersonal Skills Dimension

\begin{tabular}{|c|c|c|c|}
\hline Indicators & Mean & Standard deviation & Category \\
\hline Self-awareness & 3.32 & 0.62 & Half \\
\hline Self-management & 3 & 0.68 & Half \\
\hline Motivation & 2.92 & 0.71 & Half \\
\hline
\end{tabular}

The results obtained showed that the Self-Awareness indicator obtained an average of 3.32, which placed it in the middle category with a deviation of 0.62 , which indicated low dispersion among the data. Similarly, Autogestion obtained an average of 3 and was classified in the middle category with a deviation of 0.68 , which showed low dispersion of the data. Finally, in the Motivation, an average of 2.92 was obtained, which placed it in the middle category and with a deviation of 0.71 , which denoted a low dispersion.

Next, we analyzed the trend of the answers obtained in the questions that qualify the Intrapersonal Competence dimension, as evidenced in Table 3.

TABLE III. Frequency of the intrapersonal dimension

\begin{tabular}{|c|c|c|c|c|c|}
\hline Indicators & Items & Never & Almost never & Sometimes always & Always \\
\hline \multirow{5}{*}{ Self-awareness } & 1 & " & $6.70 \%$ & $40 \%$ & $53.30 \%$ \\
\hline & 2 & " & $6.70 \%$ & $53.30 \%$ & $40 \%$ \\
\hline & 3 & " & $6.70 \%$ & $46.70 \%$ & $46.70 \%$ \\
\hline & 4 & " & $13.30 \%$ & $26.70 \%$ & $60 \%$ \\
\hline & 5 & " & $6.70 \%$ & $46.7 \%$ & $46.7 \%$ \\
\hline \multirow{5}{*}{$\begin{array}{c}\text { Self- } \\
\text { management }\end{array}$} & 6 & " & $26.70 \%$ & $53.30 \%$ & $20 \%$ \\
\hline & 7 & " & $20 \%$ & $46.70 \%$ & $33.30 \%$ \\
\hline & 8 & " & $6.70 \%$ & $66.70 \%$ & $26.70 \%$ \\
\hline & 9 & " & $20 \%$ & $66.70 \%$ & $13.30 \%$ \\
\hline & 10 & $6.70 \%$ & $20 \%$ & $60 \%$ & $13.30 \%$ \\
\hline \multirow{5}{*}{ Motivation } & 11 & $26.70 \%$ & $53.30 \%$ & $20 \%$ & " \\
\hline & 12 & ", & $20 \%$ & $66.70 \%$ & $13.30 \%$ \\
\hline & 13 & " & $13.30 \%$ & $73.30 \%$ & $13.30 \%$ \\
\hline & 14 & " & $6.70 \%$ & $53.30 \%$ & $33.30 \%$ \\
\hline & 15 & $6.70 \%$ & $20 \%$ & $60 \%$ & $6.70 \%$ \\
\hline
\end{tabular}

With respect to the above, it can be observed that in a matter of self-knowledge, respondents always opted for options and sometimes, which means that they are aware of and respect each other's space and have knowledge about their aspirations and goals.

In the Self-management indicator, respondents showed limitation, because less than half accept when they make an error, which limits their awareness of the impact of their actions. Because of this they have little control when dealing with hostile people and find it difficult to maintain harmony in the work environment.

Regarding the Motivation indicator, there were found weaknesses highlighted in the leaders, because there was no commitment to the objectives of the organization, looking for few alternatives to change a failure and have little impact on their subordinates. That is why no progress in innovation is reflected.

On the other hand, the results of the evaluation of the Interpersonal Competences of emotional intelligence, on the 4th level hospital leaders, can be evidenced in Table 4. 
TABLE IV. Dimension: Interpersonal Competencies

\begin{tabular}{|c|c|c|c|}
\hline Indicators & Mean & Standard deviation & Category \\
\hline Social conscience & 3.11 & 0.84 & Half \\
\hline Relationship management & 2.89 & 0.87 & Half \\
\hline
\end{tabular}

In Interpersonal Competencies, it can be observed that the Social Awareness indicator obtained an average of 3.11 , which placed it in the middle category with a deviation of 0.84 , this indicated a low dispersion of the data with respect to the average. Similarly, the indicator Relationship Management was positioned in the middle category with an average of 2.89 and a deviation of 0.77 , which indicated a low dispersion of the data with respect to its average.

Likewise, a frequency analysis of the answers obtained from the respondents was carried out, as can be seen in Table 5.

TABLE V. Frequency of the dimension Interpersonal competences

\begin{tabular}{|c|c|c|c|c|c|}
\hline Indicators & Items & Never & Almost never & Sometimes always & Always \\
\hline \multirow{7}{*}{ Social conscience } & 16 & " & $6.70 \%$ & $60 \%$ & $33.30 \%$ \\
\hline & 17 & " & $6.70 \%$ & $46.70 \%$ & $46.70 \%$ \\
\hline & 18 & $13.30 \%$ & $20 \%$ & $33.30 \%$ & $33.30 \%$ \\
\hline & 19 & " & $6.70 \%$ & $53.30 \%$ & $40 \%$ \\
\hline & 20 & $20 \%$ & $33.30 \%$ & $33.30 \%$ & $13.30 \%$ \\
\hline & 21 & " & $20 \%$ & $13.30 \%$ & $66.70 \%$ \\
\hline & 22 & " & $13.30 \%$ & $66.70 \%$ & $20 \%$ \\
\hline \multirow{6}{*}{$\begin{array}{l}\text { Relationship } \\
\text { management }\end{array}$} & 23 & " & $46.70 \%$ & $40 \%$ & $13.30 \%$ \\
\hline & 24 & " & " & $80 \%$ & $20 \%$ \\
\hline & 25 & $"$ & $6.70 \%$ & $80 \%$ & $13.30 \%$ \\
\hline & 26 & $13.30 \%$ & $20 \%$ & $53.30 \%$ & $13.30 \%$ \\
\hline & 27 & $13.30 \%$ & $20 \%$ & $20 \%$ & $6.70 \%$ \\
\hline & 28 & " & $13.30 \%$ & $66.70 \%$ & $20 \%$ \\
\hline
\end{tabular}

Regarding the above, in the indicator of Social Awareness, respondents opted mostly for the response Sometimes, which represents a low sensitivity towards others on the part of the leaders and prevents a positive development of the staff. This type of behaviors only reflects them towards their subordinates, due to their superiority at the hierarchical level.

On the other hand, in the indicator Relationship Management, the respondents showed that they recognize their limits when facing conflict situations in the work areas with adequate solutions and showed an effort to encourage teamwork in everyday tasks.

Taking into account what has been described, it can be stated that it is necessary to develop skills in Relationship Management and Social Awareness in the leaders of level 4th hospitals in Zulia, through the development and training of the personnel they manage.

Then, the analysis of the data on the variable Effective leadership was carried out, where two dimensions were considered: Leadership style and Leadership approaches. The first one divides into: Autocratic, Democratic and Laissez faire. While, in the second they are: Innovative, Charismatic, Political and Visionary.

Regarding the leadership style dimension, the results obtained from the survey can be seen in Table 6.

TABLE VI. Dimension: Leadership style

\begin{tabular}{|c|c|c|c|}
\hline Indicators & Mean & Standard deviation & Category \\
\hline Autocratic & 2.93 & 0.94 & Half \\
\hline Democratic & 3.16 & 0.78 & Half \\
\hline Laissez faire & 2.91 & 1.00 & Half \\
\hline
\end{tabular}


It can be seen that the indicators were located in the Media category, which evidences the low presence of these leadership styles in the heads of hospitals of level 4th of Zulia. On the other hand, the percentages of frequencies of the indicators studied were grouped, according to the questionnaire response options, as can be seen in Table 7.

TABLE VII. Frequency of the dimension Leadership style

\begin{tabular}{|c|c|c|c|c|c|}
\hline Indicators & Items & Never & Almost never & Sometimes always & Always \\
\hline \multirow{8}{*}{ Autocratic } & 1 & $20 \%$ & $20 \%$ & $40 \%$ & $20 \%$ \\
\hline & 2 & $13.30 \%$ & $6.70 \%$ & $40 \%$ & $40 \%$ \\
\hline & 3 & $26.70 \%$ & $13.30 \%$ & $40 \%$ & $20 \%$ \\
\hline & 4 & $6.70 \%$ & $20 \%$ & $20 \%$ & $26.70 \%$ \\
\hline & 5 & $13.30 \%$ & $6.70 \%$ & $46.70 \%$ & $33.30 \%$ \\
\hline & 6 & " & " & $66.70 \%$ & $33.30 \%$ \\
\hline & 7 & $6.70 \%$ & $6.70 \%$ & $40 \%$ & $46.70 \%$ \\
\hline & 8 & $6.70 \%$ & $26.70 \%$ & $46.70 \%$ & $20 \%$ \\
\hline \multirow{9}{*}{ Democratic } & 9 & $" \prime$ & $13.30 \%$ & $33.30 \%$ & $53.30 \%$ \\
\hline & 10 & " & $26.70 \%$ & $60 \%$ & $13.30 \%$ \\
\hline & 11 & " & $26.70 \%$ & $60 \%$ & $13.30 \%$ \\
\hline & 12 & $6.70 \%$ & $6.70 \%$ & $66.70 \%$ & $20 \%$ \\
\hline & 13 & $"$ & $"$ & $53.30 \%$ & $46.70 \%$ \\
\hline & 14 & " & $40 \%$ & $20 \%$ & $40 \%$ \\
\hline & 15 & " & $13.30 \%$ & $53.30 \%$ & $33.30 \%$ \\
\hline & 16 & $6.70 \%$ & $6.70 \%$ & $73.30 \%$ & $13.30 \%$ \\
\hline & 17 & "' & $6.70 \%$ & $53.30 \%$ & $40 \%$ \\
\hline \multirow{7}{*}{ Laissez faire } & 18 & $6.70 \%$ & $33.30 \%$ & $40 \%$ & $20 \%$ \\
\hline & 19 & " & $60 \%$ & " & $40 \%$ \\
\hline & 20 & $20 \%$ & $13.30 \%$ & $20 \%$ & $46.70 \%$ \\
\hline & 21 & $20 \%$ & $13.30 \%$ & $20 \%$ & $46.70 \%$ \\
\hline & 22 & $13.30 \%$ & $13.30 \%$ & $20 \%$ & $53.30 \%$ \\
\hline & 23 & $6.70 \%$ & $20 \%$ & $33.30 \%$ & $40 \%$ \\
\hline & 24 & $13.30 \%$ & " & $66.70 \%$ & $20 \%$ \\
\hline
\end{tabular}

Table 7 shows the trends of the answers provided by the heads of hospitals of the 4th level of the State of Zulia, where, according to the frequency of responses of the Autocratic indicator, it is inferred that these are identified proportionally with This, because they do not impose their ideas directly on others but if at the time of giving their opinion, they do so firmly and maintain their position.

The results of the Democratic indicator mark the trend of the heads of the division of human resources and heads of sections of the University Hospitals of Maracaibo and General del Sur, where it is evident that a significant group of the respondents in some occasions encourage their subordinates to Take risks and make them feel important part of the organization. On the other hand, a significant group of these rarely takes into account the opinion of their collaborators.

In the Laissez Faire indicator, there was a tendency on the part of the managers to take problems calmly, where the leader's lack of confidence in his workers is highlighted, because the latter rarely delegates high priority problems to them, while in a few Sometimes it deals with small problems.

The results shown indicate that with regard to the Autocratic indicator, managers have problems when expressing what they feel about their employees, for which it is necessary to develop interpersonal competencies of emotional intelligence, in order to recognize what they feel and want to express. On the other hand, the Democratic indicator showed good persuasion skills, but it must be better in demonstrating its intentions. Finally, in the Laissez Faire indicator it is evident that the bosses do not delegate important tasks to their 
subordinates, for which reason they must be aware of the functions of their employees, in order to prevent possible problems.

In terms of the Leadership Approaches dimension, the averages and standard deviation were classified with respect to the indicators, as shown in Table 8.

TABLE VIII. Dimension of Leadership Approaches

\begin{tabular}{|c|c|c|c|}
\hline Indicators & Mean & Standard deviation & Category \\
\hline Innovative & 2.89 & 1.04 & Half \\
\hline Charismatic & 3.07 & 0.96 & Half \\
\hline Political & 2.9 & 0.98 & Half \\
\hline Visionary & 3 & 0.88 & Half \\
\hline
\end{tabular}

In the Innovative indicator, the average was 2.89 with a deviation of 1.04 , while the Charismatic had an average of 3.07 with a deviation of 0.96 , followed by the Political indicator, which obtained an average of 2.90 and a deviation of 0.98 , and the Visionary indicator with an average of 3 and deviation of 0.88 .

Likewise, we grouped the frequencies of the answers obtained IN THE questionnaire carried out by the managers, as can be seen in Table 9 .

TABLE IX. Frequency of the dimension of Leadership Approaches

\begin{tabular}{|c|c|c|c|c|c|}
\hline Indicators & Items & Never & Almost never & Sometimes always & Always \\
\hline \multirow{6}{*}{ Innovative } & 25 & "' & "' & $80 \%$ & $20 \%$ \\
\hline & 26 & $6.70 \%$ & $26.70 \%$ & $33.30 \%$ & $33.30 \%$ \\
\hline & 27 & $53.30 \%$ & $13.30 \%$ & $20 \%$ & $13.30 \%$ \\
\hline & 28 & $6.70 \%$ & $6.70 \%$ & $26.70 \%$ & $60 \%$ \\
\hline & 29 & $6.70 \%$ & "' & $46.70 \%$ & $46.70 \%$ \\
\hline & 30 & $13.30 \%$ & $53.30 \%$ & ", & $33.30 \%$ \\
\hline \multirow{6}{*}{ Charismatic } & 31 & " & $26.70 \%$ & $20 \%$ & $53.30 \%$ \\
\hline & 32 & $"$ & " & $33.30 \%$ & $66.70 \%$ \\
\hline & 33 & $13.30 \%$ & $26.70 \%$ & "' & $60 \%$ \\
\hline & 34 & $13.30 \%$ & " & $66.70 \%$ & $20 \%$ \\
\hline & 35 & $13.30 \%$ & $40 \%$ & $33.30 \%$ & $13.30 \%$ \\
\hline & 36 & $6.70 \%$ & $20 \%$ & $40 \%$ & $33.30 \%$ \\
\hline \multirow{7}{*}{ Political } & 37 & $33.30 \%$ & $26.70 \%$ & $26.70 \%$ & $13.30 \%$ \\
\hline & 38 & $20 \%$ & $13.30 \%$ & $33.30 \%$ & $33.30 \%$ \\
\hline & 39 & "' & " & $53.30 \%$ & $46.70 \%$ \\
\hline & 40 & $13.30 \%$ & $6.70 \%$ & $40 \%$ & $40 \%$ \\
\hline & 41 & " & $46.70 \%$ & $26.70 \%$ & $26.70 \%$ \\
\hline & 42 & $13.30 \%$ & $13.30 \%$ & $60 \%$ & $13.30 \%$ \\
\hline & 43 & ' & $26.70 \%$ & $26.70 \%$ & $46.70 \%$ \\
\hline \multirow{7}{*}{ Visionary } & 44 & $26.70 \%$ & $33.30 \%$ & $20 \%$ & $20 \%$ \\
\hline & 45 & "' & $20 \%$ & $40.00 \%$ & $40 \%$ \\
\hline & 46 & $13.30 \%$ & "' & $66.70 \%$ & $20.00 \%$ \\
\hline & 47 & $"$ & $33.30 \%$ & $40 \%$ & $27 \%$ \\
\hline & 48 & " & $40 \%$ & $20 \%$ & $40.00 \%$ \\
\hline & 49 & " & $20 \%$ & $66.70 \%$ & $13.30 \%$ \\
\hline & 50 & " & $6.70 \%$ & $26.70 \%$ & $26.70 \%$ \\
\hline
\end{tabular}


After analyzing the data of the Leadership Approach dimension, it is observed that regarding the Innovation indicator, the heads of the division of human resources and the supervisors of the sections of the hospitals of the 4th level of the State of Zulia, were strategists at the time of being innovative In the same way they enjoy the challenges, but mostly they do not know the strengths of their work team.

On the other hand, according to the Charisma indicator, it is considered that the leaders and supervisors present traits of charismatic leadership, this is because they are able to freely show their feelings towards their subordinates, share achievements and failures with their co-workers. In the same way they need to recognize the work of the subordinates and trust them, to cause a positive impact on the workers, improving the fluidity of the work.

The results of the Political indicator show certain tendencies, since they do not have security to improve they prefer not to promise anything, but they have the ability to convince their workers and support those who follow them as a leader.

Finally, regarding the Leadership Approach dimension, the Visionary indicator was evaluated, highlighting that they learn from their mistakes, they make new ideas known. The need to reinforce this approach can be inferred with the competencies of emotional intelligence such as interpersonal intelligence, in order to express to their subordinates what they expect from them and to clearly disclose the path they wish to take.

When performing the analysis of the indicators, the Pearson correlation formula was used to determine the relationship between Emotional Intelligence and Effective Leadership with a result of 0.79, that is, the correlation is considerable, according to the Table 10, where Pearson's correlation interpretation scale is evidenced. This is consistent with the idea put forward by (Spano-Szekely et al., 2016) who state that there is a positive relationship between emotional intelligence and transformational leadership, which is a type of effective leadership in female nurses and obtained a correlation of 0.47. Similarly (Batista and Bermúdez, 2009) estimated a positive relationship between emotional intelligence and female leadership with a correlation of 0.69. The foregoing indicates that certain aspects of emotional intelligence are related to leadership.

TABLE X. Interpretation scale for the Pearson correlation

\begin{tabular}{|c|c|}
\hline Correlation & Interpretation \\
\hline-1.00 & perfect negative correlation \\
\hline-0.90 & very strong negative correlation \\
\hline-0.75 & considerable negative correlation \\
\hline-0.50 & medium negative correlation \\
\hline-0.10 & weak negative correlation \\
\hline 0.00 & where is no correlation between the variables \\
\hline 0.10 & medium positive correlation \\
\hline 0.50 & considerable positive correlation \\
\hline 0.75 & very strong positive correlation \\
\hline 0.90 & perfect positive correlation \\
\hline 1.00 &
\end{tabular}

After finalizing the analysis of results, the strengths and weaknesses found in the division heads of human resources and supervisors of the sections of the University Hospitals in Maracaibo and General del Sur in the competencies of emotional intelligence and effective leadership (Table 11). 
TABLE XI. Diagnosis chart of emotional intelligence and effective leadership

\begin{tabular}{|c|c|c|}
\hline Dimension & Strengths & Weaknesses \\
\hline $\begin{array}{l}\text { Intrapersonal } \\
\text { Skills }\end{array}$ & $\begin{array}{l}\text { * Leaders know the emotions they experience } \\
\text { * They know the practices that affect } \\
\text { relationships } \\
\text { * They have the confidence to solve problems }\end{array}$ & $\begin{array}{l}\text { * Difficulty dealing with hostile people } \\
\text { * Scarce harmony in the work environment } \\
\text { * Little identified with the objectives of the } \\
\text { institution }\end{array}$ \\
\hline $\begin{array}{l}\text { Intrapersonal } \\
\text { competencies }\end{array}$ & $\begin{array}{l}\text { * Set goals for the common good in others } \\
\text { * They are interested in providing immediate } \\
\text { response to the hospital community }\end{array}$ & $\begin{array}{l}\text { * Little sensitivity to the needs of others } \\
\text { * Little concern for the development of } \\
\text { your work team } \\
\text { * Little assertiveness in the handling of } \\
\text { labor conflicts }\end{array}$ \\
\hline $\begin{array}{l}\text { Leadership } \\
\text { style }\end{array}$ & $\begin{array}{l}\text { * Keep ideas and opinions firm } \\
\text { * Stimulates workers to assume high levels of } \\
\text { risk } \\
\text { * Sometimes they take problems calmly }\end{array}$ & $\begin{array}{l}\text { * Attributes responsible for failures to } \\
\text { others* They consult little to the workers } \\
\text { the proposals and new projects* Little } \\
\text { moderation when expressing } \\
\text { dissatisfaction }\end{array}$ \\
\hline $\begin{array}{l}\text { Leadership } \\
\text { Approaches }\end{array}$ & $\begin{array}{l}\text { * They are strategists to convince others of } \\
\text { something new } \\
\text { * He likes challenges } \\
\text { * They present new ideas to analyze them }\end{array}$ & $\begin{array}{l}\text { * They do not know the strengths of their } \\
\text { collaborators } \\
\text { * They do not recognize the work of } \\
\text { outstanding workers } \\
\text { * Lack of cohesion in terms of teamwork }\end{array}$ \\
\hline
\end{tabular}

\section{CONCLUSION}

It was determined that the emotional intelligence and effective leadership of the managers and supervisors of the Hospitals of the 4th level of the State of Zulia, should be able to identify what could harm their integrity and that of their workers, in the same way the way to persuade hostile situations to regain harmony in the work environment. In interpersonal skills it is necessary to strengthen aspects such as social awareness and relationship management.

Regarding styles, characteristics of these styles were identified, as is the case of self-critical leadership, where the need to improve the skills of intrapersonal emotional intelligence is identified, which allows self-awareness of their feelings and self-management when expressing them. Regarding democratic leadership, respondents showed ability to persuade their subordinates and listen to ideas on several occasions, but fail to give their ideas, therefore it is necessary to develop skills of intrapersonal and interpersonal emotional intelligence, in order to create a better work environment. Finally, in Laissez faire leadership styles, it can be inferred that although bosses do not delegate the problems of highest priority to their workers, they must have a strong control over the functions performed by their workers, in order to avoid causing a type of problem, so you must develop the competence of interpersonal emotional intelligence specifically relationship management.

With respect to leadership approaches, it can be inferred that they are an important part since they seek to be linked to human resources, therefore all approaches tried to make a positive link with employees. It is considered that leadership approaches must be reinforced through emotional intelligence competencies.

Finally, a strong relationship between emotional intelligence and effective leadership was found, with which they considered strengthening the leadership in the hospitals of the 4th level of the State of Zulia, with various resources, such as: Dictate workshops for the strengthening of intrapersonal competences and interpersonal, guide and improve the practices used.

\section{REFERENCES}

[1] A. Abraham, “The need for the integration of emotional intelligence skills in business education,” The Business Renaissance Quarterly, vol. 1, no. 3, pp. 65-80, 2006.

[2] D. Miscenko and H. Guenter, "Day D. Am I a leader? Examining leader identity development over time," The Leadership Quarterly, vol. 28, no. 5, pp. 605-620, 2017.

[3] R. Golmoradi and F. Sattari, "The effects of Social Capital and Leadership Styles on Organizational Learning," Procedia - Social and Behavioral Sciences, vol. 230, pp. 372-378, 2016.

[4] C. García, J. Carreón, A. Sánchez, F. Sandoval, M. Morales, "Confiabilidad y validez de un instrumento que mide el liderazgo y la gestión educativa,” Ehquidad International Welfare Policies and Social Work Journal, vol. 5, pp. 109-130, 2016.

[5] J.C. Espinosa, F. Contreras, G.A. Esguerra and I. Fierro, "Validación preliminar del modelo de liderazgo espiritual de Fry en trabajadores colombianos y ecuatorianos,” Acta Colombiana de Psicología, vol. 20, no. 1, pp. 177-189, 2017.

[6] B. Loerakker and F. Winden, "Emotional Leadership in an Intergroup Conflict Game Experiment," Journal of Economic Psychology, vol. 63, pp. 143-167, 2017.

[7] H.M. Yusof, H.A. Kadir and M. Mahfar, “The Role of Emotions in Leadership,” Asian Social Science, vol. 10, no. 10, pp. 41-49, 2014. 
[8] J. Rode, M. Arthaud-Day, A.Ramaswami and S.A. Howes, "Time-lagged study of emotional intelligence and salary," Journal of Vocational Behavior, vol. 101, pp. 77-89, 2017.

[9] C. Mayer, R. Oosthuizen and S. Surtee, "Emotional intelligence in South African women leaders in higher education," SA Journal of Industrial Psychology, vol. 43, 2017.

[10] D. Goleman, Leadership the power of emotional intelligence. Massachusetts: More than sound, 2011.

[11] J. McLeskey and N.L. Waldron, "Effective leadership makes schools truly inclusive," Phi Delta Kappan, vol. 96, no. 5, pp. 68-73, 2015.

[12] Y. Ma, R.K. Kit and E.W. Ming, "Effective leadership for crowd evacuation,” Physica A: Statistical Mechanics and its Applications, vol. 450, pp. 333-341, 2016.

[13] D. Noureddine, "The Problem of Effective Leadership from the Perspective of Corporate Management Development," Procedia Social and Behavioral Sciences, vol. 181, pp. 62-71, 2015.

[14] J. Delmatoff, and I.R. Lazarus, “The Most Effective Leadership Style for the New Landscape of Healthcare,” Journal of Healthcare Management, vol. 59, no. 4, pp. 245-249, 2014.

[15] J. Stone, E.L. Aveling, M. Frean, M. Shields, C. Wright, F. Gino, T. Sundt and S. Singer, "Effective Leadership of Surgical Teams: A Mixed Methods Study of Surgeon Behaviors and Functions,” The Annals of Thoracic Surgery, vol. 104, no. 2, pp. 530-537, 2017.

[16] Hernández, Fernández and Baptista. Metodología de la Investigación. México: Editorial McGraw-Hill, 2010.

[17] S. Fontes, C. García, L. Quintanilla, R. Rodríguez, P. Rubio and E. Sarriá, Fundamentos de Investigación en Psicología. Madrid: UNED - Universidad Nacional de Educación a Distancia, 2015.

[18] C. Oviedo and A. Campo-Arias, “Aproximación al uso del coeficiente alfa de Cronbach,” Revista Colombiana de Psiquiatría, vol. 34, no. 4, pp. 572-580.

[19] I. Grande and E. Abascal, Fundamentos y técnicas de investigación comercial. Madrid: ESIC editorial.

\section{AUTHOR PROFILE}

Marianela Mendoza works as Autonomous Service at the University Hospital of Maracaibo (Venezuela). Mrs. Mendoza completed his magister from UNEFA (Venezuela).

Raul J. Martelo works as full-time professor at the University of Cartagena (Colombia). Mr. Martelo completed his magister from Industrial University of Santander (Colombia). Mr. Martelo completed his undergraduate in Systems Engineering at the Industrial University of Santander.

Diofanor Acevedo Correa works as full-time professor in the University of Cartagena (Colombia). Dr. Acevedo completed his doctorate from University of Valle (Cali-Colombia). Mr. Acevedo completed his undergraduate in Food Engineering and Pharmaceutical Chemistry at the University of Cartagena. 